\title{
High efficiency marine propulsion plant
}

\author{
Ruihao Wang \\ Power System and Automation, School of North China Electric Power University, \\ Baoding, Hebei, China \\ E-mail: 799309482@qq.com
}

\begin{abstract}
The device is based on the principle of gear transmission and the design is to improve traditional paddle wheel drive in which exist defects, by using the synchronous effect of the odd gears, making the ship with propulsion device of a water shifting plate in a vertical state, namely propeller thrust direction and hull forward in the same direction, to overcome the traditional problem of an angle existing between the paddle rotating shifting water thrust direction and the hull forward, which can be maintained in the working state of the highest efficiency. Compared with the traditional paddle propeller this improvement greatly reduces energy consumption to energy, power saving, achieving the goal of efficiency improvement. At the same time, this set of measures, all the basic mechanical transmission theory of gear meshing, the constructed, without increasing other electronic equipment, does not consume other energy, making the whole device reliable, economic, durable and easy to maintain a yet higher goal.
\end{abstract}

\section{Keywords_-gear transmission, vertical state, power saving}

\section{I.Development Background and Significance}

Paddle propeller is a ship advancing tool. It is local into the water of marine propellers, and is mounted on both sides of the ship or the tail, similarly in shape to a wheel. To push the ship forward, it is provided with a plurality of the paddle blade in the wheel circumference, rotated by a paddle wheel, leaf allocation of water. Paddle propeller is mainly used in thrust, draft shallow, low speed ships, such as cleaning ships on water, park sightseeing boats, river cruise ships.

In the prior technology some low-speed ships in the battery for power are most of the fixed paddle. With this device angle changes continuously in the process of shifting water, it will produce useless acting force, thus wasting a lot of energy. Based on this situation, we design a new paddle propeller. The propeller with movable paddle wheel to plate water skillfully uses gear transmission mechanism to make the deflector plate water in water always keep a vertical state of allocation of water. The dial plate water thrust is all for acting, so as to effectively improve the efficiency of propeller and save the ship power consumption.

\section{Design Ideas and Basic Principles}

\section{A. Design Ideas}

Through the analysis of the existing ship paddle propeller design method, we collect and correct the shortcomings, and bring out a new type of high efficiency paddle propeller.
Traditional paddle: relying solely on a main shaft to drive the rotary wheel, along the radial direction of the wheel, out are many water shifting plate called "paddle" And under the rotating disk drive, the paddles propeller water to provide the force

The improved paddle: The spindle drives four rotating arms to rotate, In the rotating arm, an odd number of transmission gears are arranged and the same as each other and are engaged. Using the synchronous effect of the odd gears, the dial plate water is always in vertical state allocating water.

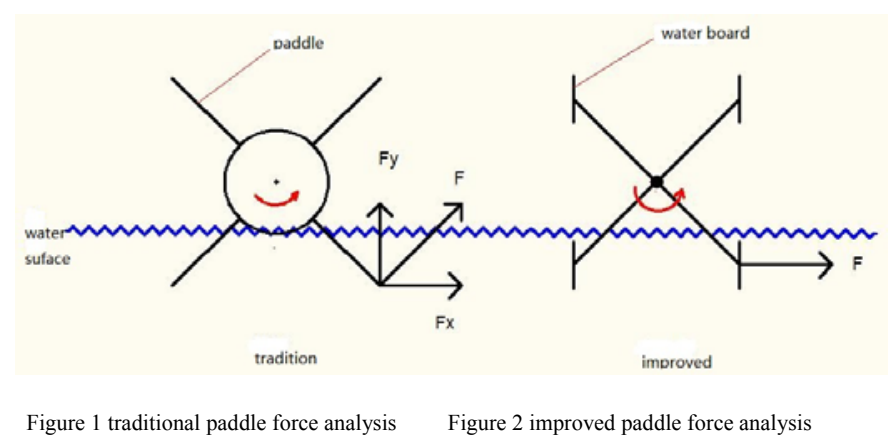

Detailed explanation to the differences of the two types in the thrust.

As is shown in Figure 1, the counterclockwise rotation of the traditional paddle will produce thrust $F$ in water process. It can be decomposed into $F_{x}$ and $F_{y}$, among them, the force $F_{x}$ is used to promote the advance of the hull and component $F_{y}$ due to vertical to the hull forward direction does not work, resulting in a waste of energy. So, we design a new paddle propeller in the form of Figure2. The water plate of the propeller can always keep a vertical state in the rotating process. The resulting thrust is always kept horizontal direction, with no existence of the other direction components, so the thrust production can all be used to do work, and avoid the waste of energy. 


\section{B. The Structure of High Efficiency Propeller for Ship:}

The high efficiency propeller we designed is mainly composed of the following parts: The main shaft, the dial water plate axis, the revolving arm, the central gear, the driven gear, the gear water gear and the fixed bracket, etc.

As shown in Figure 3, the two rotating arms are 90 degrees vertically fixed by the main axis of the spindle .The same number of gears with the same number of odd diameters are arranged on one side of the rotating arm. Its arrangement way is : with center gear as the center, the other gears are arranged in four directions along the rotating arm; at the other side of the two rotating arm of the 90 degrees, a pair of rotating arms are equally mutually 90 degrees---gear is not arranged on the rotating arm; the two groups of the rotating arm are fixed by the shaft connection to make rotation of the two groups rotate synchronously The most lateral axis called the water plate axis is fixed in a vertical direction of the dial water plate, the dial water plate rotates with the axis of the water plate, to provide the water for the ship's forward.

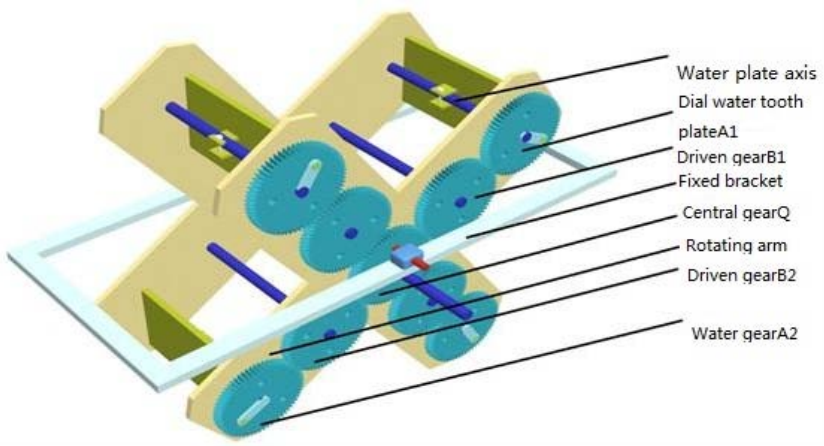

Figure 3 Schematic diagram of efficient marine propeller

\section{C.The Principle of High Efficiency of Marine Propeller}

With no fixation to the spindle, the center gear $\mathrm{Q}$ is fixed with the hull and do not rotate relatively, The center gear Q, driven gear B1 or B2 and water plate gear mesh adjacently; The water plate gear A can not rotate relatively to the plate axis; The rotating arm is fixed on the spindle. When the spindle drives the rotating arm to rotate, the driven gear B1or $\mathrm{B} 2$ will rotate, and the water plate gear A1orA2 also happens to rotate. Since the driven gear B1orB2and the water plate gear A1orA2have the same rotation angle but opposite directions, the water plate gear A1orA2and center gear remain relatively quiescent. The center gear is fixed with the ship, so the water plate gear A1orA2 remains relatively stationary to the hull. Because of the initial vertical state of the dial water plate, it will keep vertical direction in the rotation process.

\section{D.The Working Process of High Efficiency Propeller for Ship:}

We select some of the state points during the work. As is shown in Figure4, red object is a marker in the picture. It is fixed on the dial water gear. Since the dial water plate is fixed with the water plate shaft through the water plate shaft, the status of the state of the marker is also used to tell the status of the water plate. As long as the initial vertical state of the marker is initially rotated, the marker is still in the vertical state when the rotation is arbitrary, and this also shows that the water version of the dial in the rotation process can always remain upright.

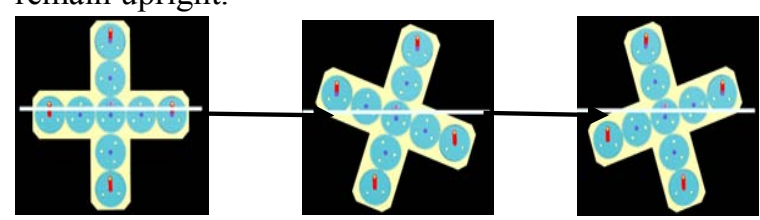

Figure 4 paddle wheel running state diagram

III.The innovation of the device

A. Comparisons of the Traditional Paddle with the Paddle Improved after

Table 1

\begin{tabular}{|l|l|l|}
\hline & Traditional paddle & The paddle improved \\
\hline Movement structure & $\begin{array}{l}\text { Motor drive spindle } \\
\text { rotation }\end{array}$ & $\begin{array}{l}\text { Motor driven rotary } \\
\text { arm rotation }\end{array}$ \\
\hline Transmission mode & $\begin{array}{l}\text { Direct drive spindle } \\
\text { rotating paddle }\end{array}$ & $\begin{array}{l}\text { The rotating arm } \\
\text { through a gear drive } \\
\text { mechanism drives the } \\
\text { rotating paddle }\end{array}$ \\
\hline Work efficiency & Low energy utilization & $\begin{array}{l}\text { High } \\
\text { utilization ;nearly one } \\
\text { time higher than the } \\
\text { traditional paddle }\end{array}$ \\
\hline
\end{tabular}

The curves of the change of force, torque and efficiency in one round

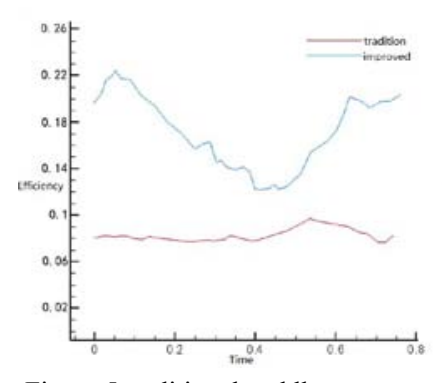

Figure 5 traditional paddle

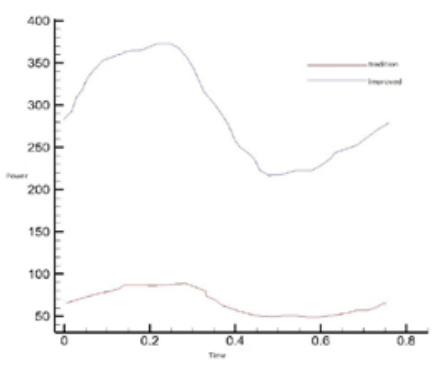

Figure 6 the paddle improved

\section{B. Innovation Points}

1)The device modifies traditional paddle wheel according to the theory of gear drive. The driving wheel and the end gear are made to remain relatively static and the shifting water plate always keeps the vertical state. The rotation does not exist transverse force thus pushing forward system efficiency 
is greatly improved. With the same forward speed, engine power is greatly reduced, to achieve the purpose of saving energy and reducing consumption.

2) Based on traditional paddle wheel and by only increasing gear, our design is ingenious, relatively easy to transform, low cost and can enhance the ship's maneuverability and flexibility.

3)The device can be widely used in the water surface cleaning ship, tourism, etc. Due to its remarkable energy saving, it can bring great economic benefits as well as have a strong promotion.

\section{Conclusion}

The water shifting plate of the propeller has remained vertical allocation of water. It always presses water when working, and can produce maximum thrust and reduce the resistance when coming out of water. The ship can save energy, and it is favorable for environmental protection. The new paddle propeller with the characters of environmental protection and energy saving, easy transformation, and energy utilization rate, has a great market space and high popularization value.

\section{References}

[1]Zhang Shukun, he Li, Zhao Qilin et al. Paddle propulsion device control and design of [J]. Electronic World, 2013,12-02

[2]Zhang Jianbo. The performance of rapid shallow paddle barge [J].Chinese Offshore Platform.1997,12-13

[3] Han Qingsong. Based on Pro / Engineer of aquatic weed harvesters paddle device modeling and simulation analysis [D]. Huhhot: Inner Mongolia Agricultural University, 2006.

[4]Zhang Shukun, He Li, Zhao Qilin ,Xie Deguan,Tangmin,Gu pingfan. Device design and control of the paddle wheel propulsion. The electronic world.2013,1 